\title{
Clinical Presentation and Surgical Outcome of Parotid Gland Tumors- Experience in ENT Department of Rajshahi Medical College Hospital
}

\author{
Subrata Ghosh, ${ }^{1}$ Milon Kumar Chowdhury, ${ }^{2}$ Enamul Haque, ${ }^{3}$ Sunandita Sarkar, ${ }^{4}$ \\ Anindita Sarkar, ${ }^{5}$ Mahmudul Haque ${ }^{6}$
}

\begin{abstract}
Objective: To assess the clinical presentation and outcome of surgical treatment of various parotid gland diseases requiring parotidectomy.

Setting \& design: this was a retrospective study conducted of all patients who underwent different types of parotidectomy in the Department of ENT of Rajshahi Medical College Hospital between January, 2014 to December, 2017.

Materials \& Methods: Patients presenting with parotid gland disorders requiring various range of parotidectomy admitted in ENT dept. RMCH were included in this study. The location of the tumor and diagnosis was confirmed in every case by advising ultrasound of the parotid region and/or computed tomography scan/MRI along with fine needle aspiration cytology of the swelling. Data regarding age, gender \& histology, operative procedure and post-operative complications were meticulously entered in a previously prepared questionnaire for this purpose. Patients were followed up for about two years.

Results: Out of 68 patients, 37 (54.4\%) were male and 31 (45.6\%) were female with age ranging from 26 to 63 yrs. with a mean age of 39.5 years. All of them presented with painless parotid lump. 55 Fifty Five Patients $(80.9 \%)$ had benign pathology while 13 patients (19.1\%) had malignancy. Superficial parotidectomy was alone in 48 patients $(70.6 \%)$, total parotidectomy in $18(26.5 \%)$ patients and extended parotidectomy was performed in 2 cases $(2.9 \%)$. The most common post-operative complication was numbness of ear lobule (gradually improving with time) in 8 patients (11.8\%), followed by transient facial nerve paresis in 7 patients $(10.3 \%)$. There was no hospital mortality.

Conclusion: Parotid gland disorders affect each gender almost equally. Most of the patients present with benign pathology, superficial parotidectomy is the commonly offered surgical management. All parotid surgeries are safely performed in Department of ENT with minimum morbidity.
\end{abstract}

Key words: Parotid gland, pleomorphic adenoma, facial nerve, superficial parotidectomy.

${ }^{1}$ Assistant Professor, Department of ENT, Rajshahi Medical College, Rajshahi

2 Junior Consultant, Department of ENT, Rajshahi Medical College Hospital, Rajshahi

${ }^{3}$ Assistant Professor, Department of ENT, Rajshahi Medical College, Rajshahi

${ }^{4}$ MS Student, Rajshahi Medical College, Rajshahi

${ }^{5}$ MD Student, Pathology, Rajshahi Medical College, Rajshahi

${ }^{6}$ Registrar, Department of ENT, Rajshahi Medical College Hospital, Rajshahi 


\section{Introduction}

The parotid gland is primarily a serous gland that is located high is the neck in the pre-auicular area extending towards the cheek. The extra-temporal facial nerve and its branches pass through the parotid gland and supply motor innervations to the muscles of facial expression. ${ }^{1}$

The parotid gland is the most common site for salivary gland tumors. The majority of tumors arises in the superficial lobe and present as slowly growing masses below the ear, in front of the ear or sometimes in the upper aspect of the neck. Less commonly, they arise from accessory parotid tissue and then present as swelling in the cheek. Rarely tumors arise from the deep lobe and then present as parapharyngeal masses with a diffuse bulge in the soft palate \& tonsillar region. ${ }^{2}$ About $80 \%$ of salivary gland tumors occur in parotid gland. The annual incidence of parotid gland tumors is 1 in $1,00,000 .^{3-4}$ In $80 \%$ of cases, it is pleomorphic adenoma while Warthin's tumors accounts for $10 \%$. Among the malignancies, mucoepidermoid carcinoma is the most common followed by adenoid cystic carcinoma. ${ }^{3-5}$ The facial nerve traverses through the parotid gland, dividing into various branches and thus devides the parotid into a large superficial lobe and a smaller deep one. Positive identification and preservation of the facial nerveis essential for preventing inadvertent facial nerve injury.

The important pointers to the facial nerve are the mastoid process, the inferior portion of the cartilaginous canal and the tragal pointer, this is termed Conley's pointer and indicates the position of the facial nerve, which lies $1 \mathrm{~cm}$ deep and inferior to its tip. The upper border of the posterior belly of the digastric muscle is another very important pointer. The main trunk of the facial nerve is located at a point where the mastoid process, the cartilaginous portion of the auditory canal and the superior belly of the digastric muscle meet. ${ }^{6}$ Neoplasms are the most common indication for parotidectomy. The vast majority of primary parotid tumors are benign, but approximately $20 \%$ are found to be malignant. In addition, regional and distant disease can metastasize to the parotid and necessitate removal for diagnosis or cure.
Inflammatory process (e.g. chronic parotitis, deep salivary calculi, or parotid abscess) are occasionally treated with total parotidectomy. Sialorrhoea is rarely treated with parotidectomy.

Fine needle aspiration cytology is one of the most important investigations for parotid disorders Ultrasonogram, CT scan, MRI are also important investigation for meticulous anatomical observation.

Superficial parotidectomy is the most common surgical procedure in parotid pathology. Total parotidectomy are done in some benign and malignant conditions, extended parotidectomy is done in a few malignant conditions. ${ }^{7-10}$ Important complications of parotid surgery are hematoma formation, flap necrosis, wound infection, temporary facial nerve weakness, the transaction of the nerve with permanent damage, sialocele formation, permanent numbness of the ear lobule due to transaction of the greater auricular nerve, Frey's syndrome, facial asymmetry and tumor recurrence.

The present study was conducted to assess the clinical presentation and surgical outcome of various parotid gland disorder that necessitated parotidectomy of ENT department of Rajshahi Medial College Hospital.

\section{Materials and Methods}

This was a retrospective study conducted of all patients who underwent various range of parotidectomy in ENT department, Rajshahi Medical College Hospital between January, 2014 and December, 2017.

The location of the tumor and diagnosis was confirmed in every case by ultrasound of the parotid region and/or CT scan, MRI along with FNAC of the swelling.

The operative procedure was designed according to the type and extent of the disorder. Superficial parotidectomy was performed for all benign tumors confined to the superficial lobe. Total parotidectomy was performed for benign tumor involving deep lobe and for malignant parotid tumor confined within the gland. Extended parotidectomy was performed for locally advanced 
malignant tumors. In every case facial nerve was identified and all the branches were traced, no nerve conductor was available in the hospital. All surgeries were performed by us in ENT Operation Theater.

The profile of the patient, presenting, feature, benign/malignant nature of the disease, FNAC report, USG report, scan report, types of surgical procedure instituted, complication encountered and histopathology reports of surgical specimens were all recorded in a previously prepared form.

\section{Results}

A detailed study of 68 patients showed that 37 (54.4\%) patients were male and 31 (45.6\%) female, with age ranging from 26 to 63 years with a mean age of 39.5 year. The majority of the patients (66\%) were in the third and fourth decades of life. The mean age in cases of malignant tumors was 46.7 years.

Swelling or lump in the parotid region constituted the most frequent presenting feature, found among all the patients. It was followed by facial palsy $4.4 \%(n=3)$ and ulceration over the lump 1.5\% $(n=1)$ cases. $80.9 \%(n=55)$ patients had benign pathology while $19.1 \%(\mathrm{n}=13)$ had malignancies. The deep lobe was involved in $7.35 \%(n=5)$ cases, while $8.8 \%(n=6)$ cases were recurrent. Table-1 shows histopathological variations of the study-

Table-1: Histopathological diagnosis among the patients $(\mathbf{N}=68)$

\begin{tabular}{|c|c|c|}
\hline Diagnosis & $\begin{array}{l}\text { Number of } \\
\text { the Pt. }\end{array}$ & Percentage \\
\hline Pleomorphic adenoma & 48 & $70.6 \%$ \\
\hline Mucoepidermoid & 5 & $8.8 \%$ \\
\hline Carcinoma & & \\
\hline Warthin's Tumour & 3 & $4.4 \%$ \\
\hline $\begin{array}{l}\text { Adenoid cystic } \\
\text { carcinoma }\end{array}$ & 4 & $5.9 \%$ \\
\hline Monomorphic adenoma & 2 & $2.9 \%$ \\
\hline $\begin{array}{l}\text { Carcinoma ex- } \\
\text { pleomorphic adenoma }\end{array}$ & 3 & $4.4 \%$ \\
\hline Chronic sialadenitis & 1 & $1.5 \%$ \\
\hline Haemangioma & 1 & $1.5 \%$ \\
\hline
\end{tabular}

The most common surgical procedure performed was superficial parotidectomy in $70.06 \%(n=48)$ patients, total parotidectomy was done in $26.5 \%$ $(\mathrm{n}=18)$ patients and extend parotidectomy was done in $2.9 \%(\mathrm{n}=2)$ cases. Table 2 shows different operative procedure in benign \& malignant parotid disorders.

Table 2: Different operative procedure in benign and malignant parotid disease

\begin{tabular}{|c|c|c|}
\hline $\begin{array}{c}\text { Type of } \\
\text { parotid disease }\end{array}$ & $\begin{array}{c}\text { Type of surgical } \\
\text { prouder }\end{array}$ & $\begin{array}{c}\text { Number } \\
\text { (Percentage) }\end{array}$ \\
\hline \multirow[t]{2}{*}{$\begin{array}{l}\text { A. Benign } \\
\text { disease }\end{array}$} & $\begin{array}{l}\text { Superficial } \\
\text { parotidectomy }\end{array}$ & $48(70.6 \%)$ \\
\hline & $\begin{array}{l}\text { Total } \\
\text { Parotidectomy (in } \\
\text { both superficial \& } \\
\text { deep lobe involved) }\end{array}$ & 7 (10.3\%) \\
\hline \multirow[t]{2}{*}{$\begin{array}{l}\text { B. Malignant } \\
\text { disease }\end{array}$} & $\begin{array}{l}\text { Total } \\
\text { Parotidectomy }\end{array}$ & 11 (16.2\%) \\
\hline & $\begin{array}{l}\text { Extended } \\
\text { parotidectomy }\end{array}$ & $2(2.9 \%)$ \\
\hline
\end{tabular}

In postoperative two years follow-up we found greater auricular nerve paresis in $11.8 \%(n=8)$ patients, transient facial nerve palsy in 10.3\% $(\mathrm{n}=7)$ patients, facial palsy in $1.45 \%(\mathrm{n}=1)$ patient. In 3 cases $(4.4 \%)$ facial nerve was deliberately sacrificed due to its involvement by the tumor.

Table 3: Table to calculate diagnostic accuracy of FNAC for diagnosing malignancy in parotid gland $(n=68)$

\begin{tabular}{lccc} 
Histopathology & \multicolumn{2}{c}{ FNAC } & Total \\
& $\begin{array}{l}\text { Positive for } \\
\text { malignancy }\end{array}$ & $\begin{array}{c}\text { Negative } \\
\text { for } \\
\text { malignancy }\end{array}$ \\
$\begin{array}{l}\text { Positive for } \\
\text { malignancy }\end{array}$ & 12 & 1 & 13 \\
$\begin{array}{l}\text { Negative for } \\
\text { malignancy } \\
\text { Total }\end{array}$ & 1 & 54 & 55 \\
& 13 & 55 & 68 \\
$\begin{array}{l}\text { Sensitivity }=92.3 \% \\
\text { Specificity }=98.18 \%\end{array}$ \\
$\begin{array}{l}\text { Positive predictive value }=92.3 \% \\
\text { Negative predictive value }=98.18 \% \\
\text { Diagnostic accuracy }=97.05 \%\end{array}$
\end{tabular}

The value of FNAC as a diagnostic tool was also assessed and was found to have $98.18 \%$ specificity and $92.3 \%$ sensitivity. The overall diagnostic accuracy was $97.05 \%$ (table-3) 


\section{Discussion}

Parotid gland tumors comprise a morphologically diverse group of tumors. Their multifaceted clinical presentation, varied morphological configuration and relatively unpredictable prognosis attract significant medical interest. This series focused on parotid gland disorders which is the commonest site for diseases among the salivary glands. It is involved by rarity of different benign and malignant conditions for which a wide range of surgical procedures are available. ${ }^{10,12-14}$

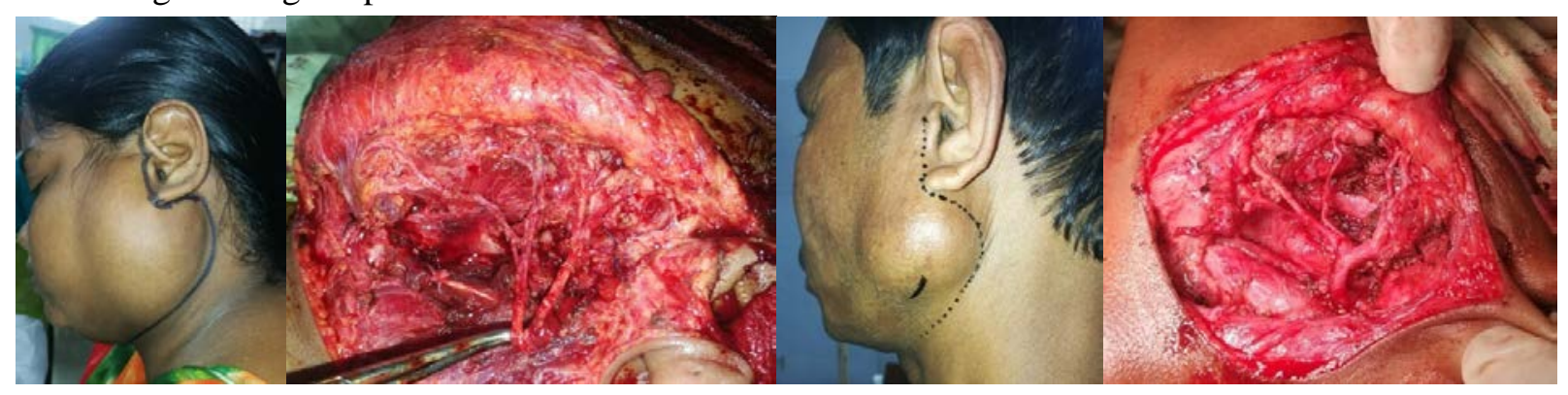

Fig: Parotid tumours preoperative and per-operative view showing branches of the facial nerve.

Patients usually present with a painless, slow growing mass. The duration of symptoms is variable. Although progression is slow, left untreated, the tumor can cause significant morbidity \& rarely, death. Involvement of the facial nerve at initial presentation almost always indicates malignancy. The likelihood of malignant transformation increases with the duration of the lesion. ${ }^{15}$ Very rarely these tumors can metastasize. ${ }^{16}$

In our study, the mean age of parotid disorder was 39.5 years confirming to several published studies. ${ }^{14,17-19}$ However, several western studies reported these disorders to be more common in relatively advanced age group. ${ }^{3,4}$ In this study, there was male predominance (54.4\%). Several published studies have reported similar more frequent involvement of male than female. ${ }^{17}$ Some published studies shows female predominance. $^{15,18,19}$

In this study, pleomorphic adenoma constituted the commonest pathology affecting the parotid gland (70.6\%). Most of the published literature has reported pleomorphic adenoma to be the commonest pathology affecting the parotid gland. ${ }^{14,17-21}$

In our study, incidence of malignant disease was $19.1 \%$. Different studies have reported variable percentage of malignancies in their patient, Kera et al, have reported $24 \%$ malignancies in parotid gland disorder. ${ }^{15}$ Takahoma et al. have reported even higher frequency of malignancies at $40 \% .{ }^{3}$ In this series the commonest malignant tumors was mucoepidermoid carcinoma followed by adenoid cystic carcinoma. These findings confirm to what is reported by most of the published literature. ${ }^{22-25}$ In this study, FNAC was found to be very useful for cytological diagnosis having $98.18 \%$ specificity \& $92.3 \%$ sensitivity. These findings confirm to what is reported by Awan et al and Hartimath et al. who have reported similar diagnostic accuracy of FNAC in parotid gland tumors. ${ }^{26,27}$ Superficial parotidectomy was alone in all our benign parotid disease involving superficial lobe as advocated by many authors. ${ }^{28-31}$ Benign parotid disease involving deep lobe and malignant parotid disease were treated with total parotidectomy preserving facial nerve.

In this study, facial nerve transient paresis occurred in $10.3 \%$ cases while $1.45 \%$ cases had facial nerve palsy. These finding conforms to most of the reported studies, however, some studies have reported as high frequency as $39 \%$ of these complications. ${ }^{15,32,33}$ 


\section{Conclusion}

Relatively young individuals of both genders are affected by parotid gland tumor that needs surgical management. Majority of the patients present as a painless lamp in parotid region, most of them have benign pathology, while a small percentage have malignancy. Superficial parotidectomy is the most commonly offered surgical procedure. Parotid surgeries are safely performed in ENT department with minimum morbidity.

\section{References}

1. Parotidectomy: overview, periprocedural care, technique. Alexander Langerman, MD; https:// emedicine.medscape.com/artical/1891043overview.

2. Mervyn Correia, Francis Pantaliao Noronha, Pandarinath Audi; Superficial parotidectomy an excellent procedure in the management of benign parotid tumors. 2016 medical journal of Dr. D.Y. Patil University, vo-9, issue 5, 600-604.

3. Takahama Junior A, Almeida OP, Kowalski LP. Parotid neoplasms; analysis of 600 patients attended at a single institution. Braz J Otorhinolaryngol 2009; 75: 497-501

4. Satko I, Stanko P, longauerova I. Salivary gland tumors treated in the stomatological clinics in Bratislave. Craniomaxillofac Surg 2000; 28:56-61.

5. Al-Khateeb TH, Ababnch KT. Salivary glands tumors in North Jordanians: a descriptive study. Oral Surge Oral Med Oral Pathol Oral Radiol Endod 2007: 103: 53-9.

6. Shah JP. Diagnostic approaches, therapeutic decisions, surgical techniques and results of treatment, In: Head and Neck Surgery. $2^{\text {nd }}$ ed. Mosby-Wolfe; 1996.

7. Quer M, Pujol A, Lopez M, Garcia J, Orus C, Sanudo JR. Parotidectomies in benign parotid tumors; "Sant Pau" Surgical extension classification. Actaotorhinolaringol Exp 2010; 6:1-5.

8. Laccourreye $\mathrm{H}$, Laccourreye $\mathrm{O}$, Cauchois $\mathrm{R}$, Jouffre V, Monard M, Brasnu D. Total conservative parotidectomy for primary benign pleomorphic adenoma of the parotid gland: a 25 year experience with 229 patients. Laryngoscope 1994; 104: 148794.

9. Johnson JT, Ferlito A, Fagan JJ, Bradley PT, Rinaldo A. Rle of limited parotidiectomy in management of pleomorphic adenoma. J Laryngol Otol. 2007; 1: 1-3.
10. Roh JL, Kim HS, Park Cl. Randomized Clinical trial comparing partial parotidecomy versus superficial or total parotidectomy. Br J Surg 2007; 94: 1081-7.

11. Chatterjee MT and Panda PK. A pathological study of benign and malignant tumor of salivary glands; MJAFI 2000; 56: 282-6.

12. Guntinus-Lichius O, Gabriel B, Klussmann JP. Risk of facial nerve palsy and severe Frey's Syndrome after conservation parotidectomy for benign disease: analysis of 610 patients. ActaOtoLarymgological 2006; 1104-9

13. Auclair PL, Ellis GL, Gnepp DR, Wenig BN, Janey CG. Salivary gland neoplasm: general considerations. In: Ellis GL, Auclair PL, Gnepp DR, editors. Surgical pathology of salivary glands. Philadelphia: WB Saunders: 1991. P. 136-64.

14. Kara MI, Goze F, Ezirganli S, Polat S, Muderris S, ElagozS. Neoplasms of Salivary Glands in a Turkish Adult Population. Med Oral Pathol oral cir Bucal 2010; 15: 880-5.

15. Ohtake S, Cheng j, Ida $H$, Suzuki M, Ohshiro K, Zhang W, et al. Precancerous foci in pleomorphic adenoma of the salivary gland: Recognition of focal carcinoma and atypical tumors cells by $\mathrm{P}_{53}$ immunohistochemistry. J Oral Pathol Med 2002; 31: 590-7.

16. Novraei SA, Ferguson MS, Clarke PM, Samdison A, Sandhsc GS, Michaels L, et al. Metastasizing pleomorphic salivary adenoma. Arch Otolaryngol Head Neck Surg 2006; 132: 788-93.

17. Musomi MA, Sohail Z, Zafar A, Malik S. Morphological pattern of parotid gland tumors. J coll physicians Surg Pak 2008; 18: 274-7.

18. Malik KA. Parotid gland tumors: a six years' experience. Pak j Surg 2007: 23: 133-5.

19. Dorairajan N. Salivary gland tumors; a 10 years retrospective study of survival in relation in size, histopathological examination of the tumors and nodal status. IntSurg 2004; 89: 140-9.

20. Silas OA, Echejoh GO, Momasseh AN, Mondong $\mathrm{BM}$; Patterns of malignant salivary gland tumors in Jos University Teaching Hospital (JUTH), Jos: a ten years retrospective study: Niger J med 2009; 18: 282-5.

21. Amirlak B. Malignant parotid tumors. December 15, 2011: (03 screens): (Cited Nov 03, 2012). Available at URL: emedicine. medscape. Com /article/ 1289616- overview.

22. Li LJ, Li Y, Wen YM, Liu H, Zhao HW. Clinical analysis of salivary gland tumors case in west China in past 50 years. Oral oncol 2008; 44:187-92. 
23. Subhashroy K. Salivary gland tumors; a single institution experience in India. $\mathrm{Br} \mathrm{J}$ Oral Maxillofacsurg 2008; 46:635-8.

24. Vargas PA, Gerhaid R, Filho A, De Castro IV VJ. Salivary gland tumors in Brazilian Population: a retrospective study of 124 cases. Rev Hosp Clin Fac Med Sao Paulo 2002; 57: 271-6.

25. Thakur J. Bilateral Parotid Tuberculosis. J Glob Infect Dis 2011; 3: 296-9.

26. Awan MA, Ahmed Z. Diagnostic value of fine needle aspiration cytology in parotid tumors. J Pak Med Assoc 2004; 54: 617-20.

27. Hartimath B, Kudva A, Singh Rathore A. Role of fine-needle aspiration cytology in swellings of the parotid region. Indian J Surg 2011; 73: 19-23.

28. Bardwil J.M. (1967): Tumors of the parotid gland: A.M.J. Surg 114: 498.
29. Dunn E.J, Kent T. Hines J. Cohn. I, Jr (1976): parotid Neoplasm's: A Report of 250 cases and reviewof the Literature. Ann Surg: 184: 500.

30. Beahrs D.H, Woolner I, B. Carveth S.W. and Devine K.D.: Surgical Management of Parotid Lesions Review of seven hundred sixty cases Arch. Surg 80: 890.

31. Laskawi R, Schott T, Mirzaie-Petri M, Schroeder M. (1996): Surgical Management of Pleomorphic Aclenomas of the parotid gland: A Follow-up study of three Methods. J. Oral Maxillofac. Surg 54:117678.

32. Shashinder S, Tang JP, Velayuthan, P; Prepageran N, Gopala KG, Kuljit S, et al. A review of parotid tumors and their management; a ten-year experience. Med J Malaysia 2009; 64:31-3.

33. Redaellide Zinis Lo. Management and prognostic factors of recurrent pleomorhpic adenoma of the parotid gland; personal experience and review of the literature. Eur Arch Otorhinolazyngol 2008; 265: 447-52.

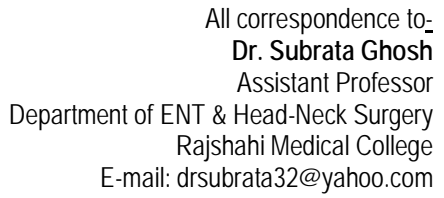

